\title{
A MECHANICAL-HYDRAULIC VIRTUAL PROTOTYPE CO-SIMULATION MODEL FOR A SEABED REMOTELY OPERATED VEHICLE
}

\author{
Dai, Y., ${ }^{* * * \#} ;$ Zhu, X. ${ }^{*} \&$ Chen, L. S. ${ }^{*}$ \\ ${ }^{*}$ College of Mechanical and Electrical Engineering, Central South University, Changsha 410083, \\ China \\ ** State Key Laboratory of Ocean Engineering, Shanghai Jiao Tong University, Shanghai 200240, \\ China \\ E-Mail: daiyu_6@aliyun.com ( ${ }^{\#}$ Corresponding author)
}

\begin{abstract}
In this study, a virtual prototype model of a seabed tracked remotely operated vehicle (ROV) is established using the program RecurDyn/Track with the integration of a user-defined subroutine for a sediment terramechanics model. Laboratory tests for evaluating the mobility performances of a small tracked vehicle are conducted to validate the computational accuracy of the new virtual prototype model. A simulation model of a load independent flow distribution (LUDV) hydraulic control system for the tracked ROV is built using the program AMESim. Based on the combined RecurDyn-AMESim interface program design, a new virtual prototype co-simulation model for the mechanical-hydraulic system of the tracked ROV is developed. Co-simulations are conducted to analyse the dynamic performances of the motor actuators in the LUDV hydraulic system and the tracked ROV mobility performances. The co-simulation results demonstrate that the developed virtual prototype model of the ROV mechanical system can accurately simulate the load of the hydraulic control system, while the LUDV hydraulic controlling method can effectively improve the operational performance of a tracked ROV multi-actuator system. This research provides an effective and valuable co-simulation modelling method for mechanical-hydraulic system optimization, performance evaluation and operational control of the seabed tracked ROV.

(Received, processed and accepted by the Chinese Representative Office.)
\end{abstract}

Key Words: Seabed Tracked Remotely Operated Vehicle (ROV), Virtual Prototype Model, Mechanical-Hydraulic Co-Simulation, Load Independent Flow Distribution (LUDV), Joint Operation Performance

\section{INTRODUCTION}

Tracked remotely operated vehicles (ROVs) are widely used in seabed engineering operations, including seabed cable laying installation, environmental exploration, mineral resources mining, etc. The locomotion and control system characteristics of ROVs directly affect their continuous operational process performance.

To estimate the locomotion dynamics of a tracked remotely operated vehicle on a seabed, Sup et al. adopted an innovative technology based on Euler parameters for evaluating the dynamic properties of a tracked mining vehicle on a deep-seabed [1] and proposed a subsystem synthesis method to analyse a multi-body model of the vehicle [2]. Kim et al. investigated the complicated dynamic responses of an articulated tracked vehicle crawling on a seabed undulating and inclined terrain [3]; furthermore, the buoyancy position effects on the dynamics of the vehicle were analysed [4]. Li and Zhong built a virtual prototype of a seabed tracked mining vehicle and conducted simulations to estimate the locomotion and trafficability performance of the vehicle [5]. Dai et al. developed new, multi-body dynamic models for two types of seafloor tracked mining vehicles and performed simulations to evaluate their mobility and trafficability performances; meanwhile, a mathematical model was established to evaluate their tractive trafficability $[6,7]$. 
To control the locomotion state and trajectory of the tracked remotely operated vehicle on the seabed, Herzog et al. established an automatic hydraulic drive mode with slip control for the tracks of a seabed tracked vehicle, and an experimental system for slip control with an automatic driving model was presented [8]. Yeu et al. proposed a path tracking method for a seabed-tracked vehicle with a vector pursuit algorithm for the motion of the vehicle to follow a specific path [9]; Yeu et al. proposed two navigation algorithms based on the kinematics of the seabed tracked mining robot, known as dead-reckoning and the extended Kalman filter [10]. Yoon et al. used the indirect Kalman filter method with inner measuring sensors to localize a seabed tracked mining robot underwater [11].

For a collaborative simulation between the mechanical and hydraulic systems, Florin presented achievements in complex modelling and simulation in mechatronics; the programs used for the kinematics and dynamics simulations of multi-body systems were emphasized [12]. Marquis-Favre et al. illustrated the use of a mechanical library for the simulation program AMESim to model a seven-body mechanism [13]. Zhang et al. presented a method to integrate the distributed simulation models at run-time, involving a computational facilities and a high-level modelling approach [14]. Huang et al. demonstrated the advantages of a dual-closed-hydraulic-circuit system for controlling the swing motion of a hydraulic shovel by simulation and validation by building a hydraulic shovel prototype [15].

Thus far, however, the complex dynamic characteristics of the mechanical and hydraulic control systems of seabed tracked remotely operated vehicles and their mutual coupling effects have not yet been ascertained. Therefore, the combined mechanical-hydraulic control systems design scheme and joint operation performance of these vehicles have yet to be evaluated and optimized because it is costly and extremely difficult to perform seabed in-situ tests. Virtual prototyping and collaborative simulation for the combined mechanical-hydraulic systems is an effective way to obtain these characteristics. This paper presents accurate and efficient virtual prototype simulation models for each system and their integration into a co-simulation model.

\section{VIRTUAL PROTOTYPE MODEL OF A SEABED TRACKED ROV}

The simulation program RecurDyn/Track, based on a recursive algorithm and a relative coordinate system, is adopted to establish a virtual prototype model of a seabed tracked ROV, as shown in Fig. 1. Table I provides its main design parameters.

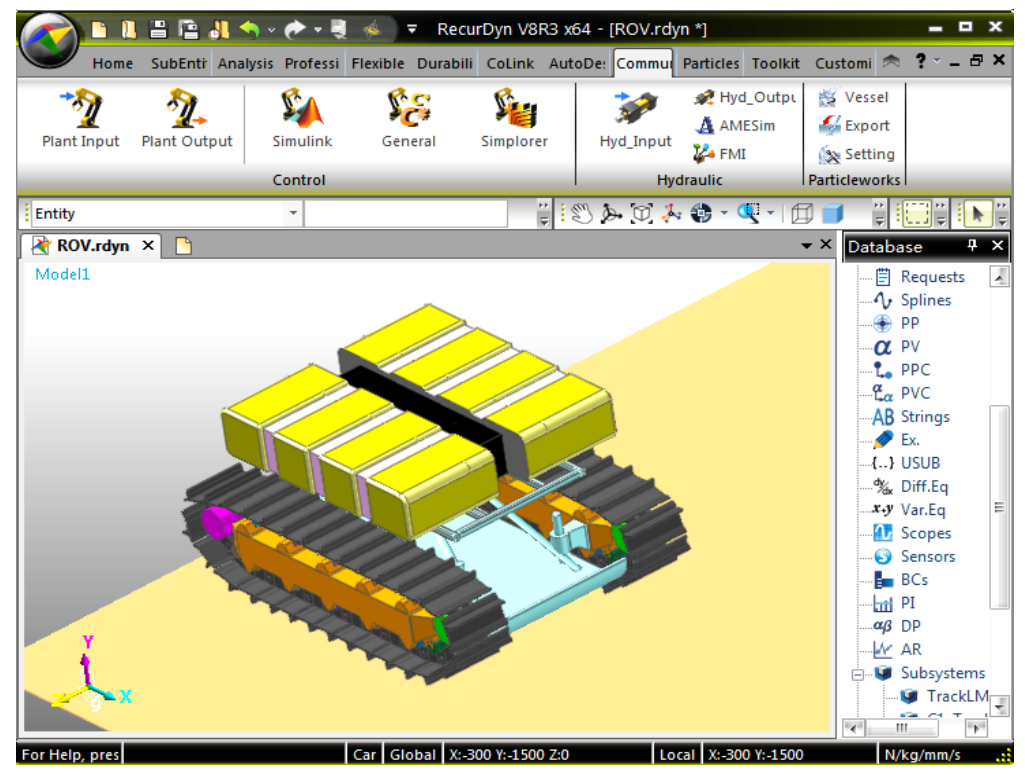

Figure 1: A 3D virtual prototype model of a seabed tracked ROV. 
Table I: Design parameters of the tracked ROV.

\begin{tabular}{|l|c|}
\hline \multicolumn{1}{|c|}{ Parameters } & Values \\
\hline Total weight underwater (tons) & 2.35 \\
\hline Overall dimension $(\mathrm{m})$ : length $\times$ width $\times$ height & $2.3 \times 1.6 \times 1.2$ \\
\hline Track contact length $(\mathrm{m})$ & 1.6 \\
\hline Track width $(\mathrm{m})$ & 0.36 \\
\hline Distance between centre lines of tracks $(\mathrm{m})$ & 1.2 \\
\hline Track pitch $(\mathrm{m})$ & 0.15 \\
\hline Grouser height $(\mathrm{m})$ & 0.05 \\
\hline
\end{tabular}

A user-defined subroutine for characterizing the special terramechanics model of the seabed sediment was developed by the $\mathrm{C}$ language in the Visual Studio.Net environment. A dynamic link library (DLL) created in Visual Studio.Net was then called by RecurDyn/Track to allow this particular sediment terramechanics model to be integrated into the RecurDyn/Track environment.

\subsection{Laboratory motion test}

A small-scale tracked vehicle was manufactured for the locomotion and trafficability analyses on soft and cohesive terrains [6], as shown in Fig. 2 a. Accordingly, a virtual prototype model was built by the above-mentioned modelling method.

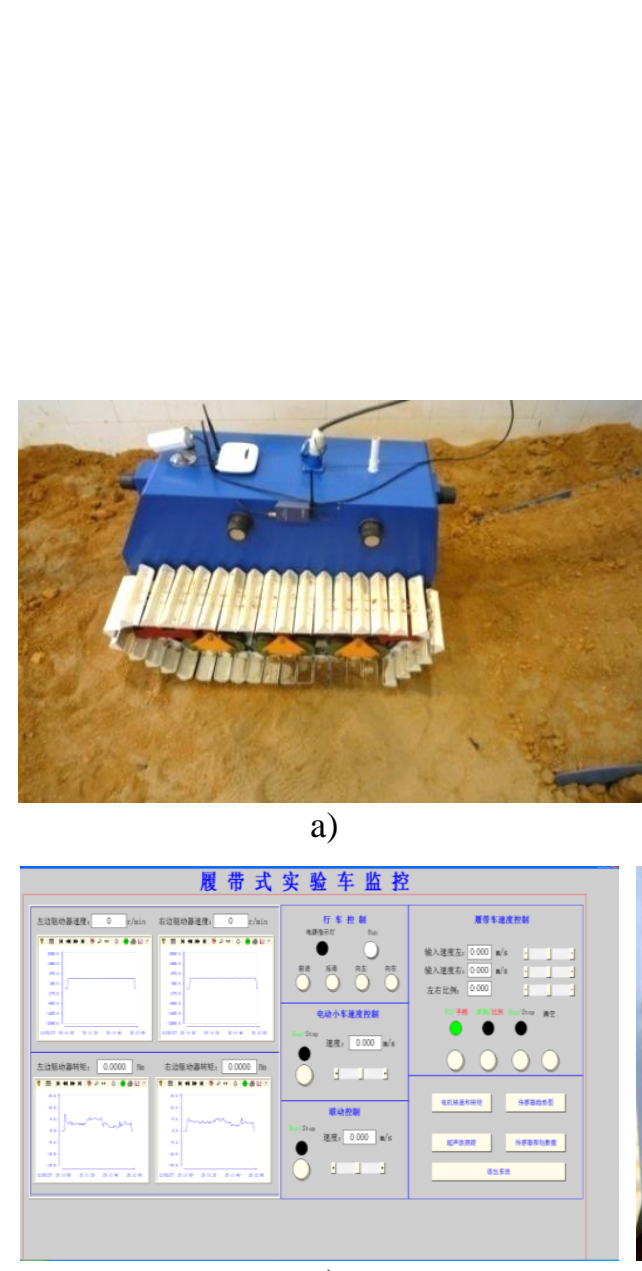

c)

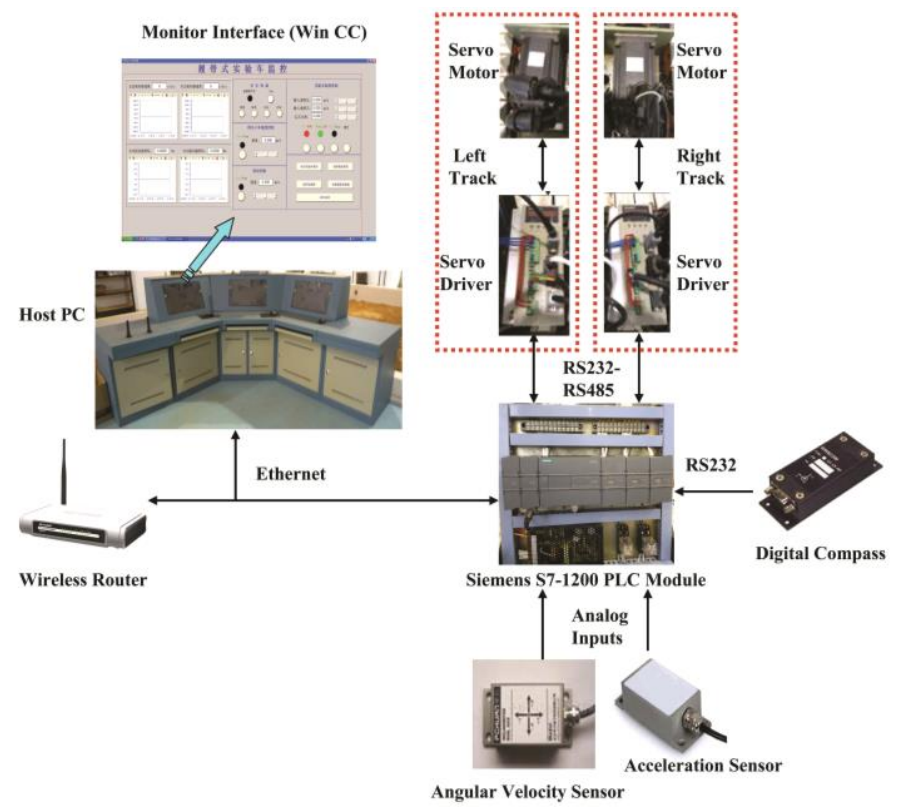

b)

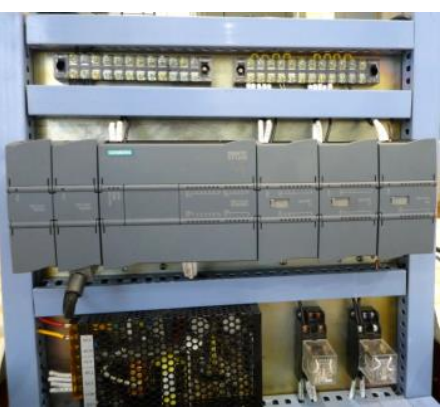

d)

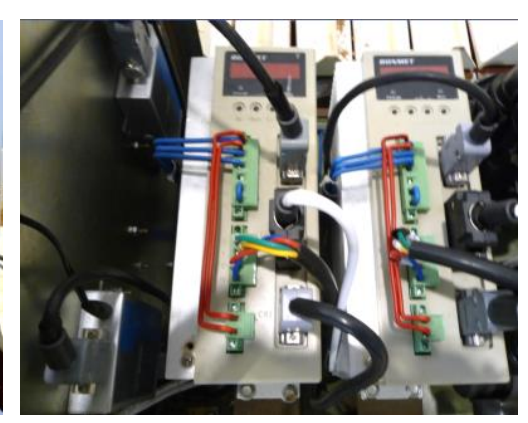

e)

Figure 2: Photograph of a laboratory tracked test vehicle: a) photo of the vehicle; b) measurement control system architecture; c) monitoring interface; d) control electroplate; and e) actuators. 
Two $1.2 \mathrm{~kW}$ permanent magnet synchronous servo motors (PMSM) were used to drive the left and right tracks independently. Absolute optical encoders were installed on the motors. The motor velocities were controlled by servo drivers, which transmitted torque and velocity data to a computer Siemens S7-1200 PLC module. A Honeywell 3-axis digital compass HMR3000 measured the pitch, roll and heading angles of the vehicle. A single axis gyroscope measured the turning angular velocity of the vehicle.

During the turning test, the input speeds for the outer and inner tracks were set to $0.16 \mathrm{~m} / \mathrm{s}$ and $0.05 \mathrm{~m} / \mathrm{s}$, respectively. Fig. 3 shows the trajectory, turning angular velocities and simulation trajectory of the vehicle, and the test results matched well with the simulation result.

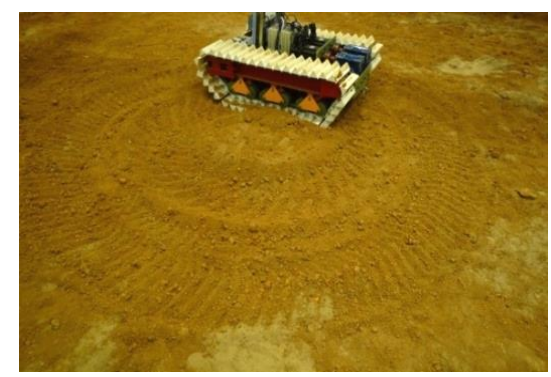

a)



b)

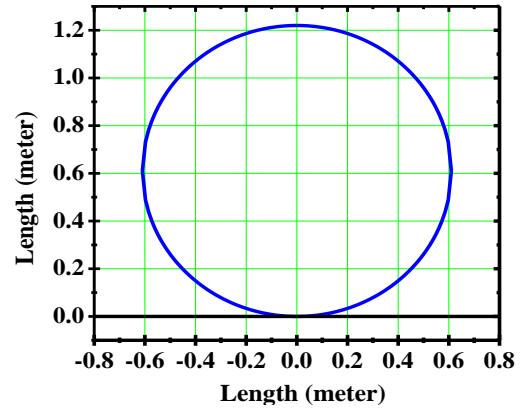

c)

Figure 3: Turning test and simulation of a tracked vehicle: a) trajectory photograph; b) turning angular velocities; and c) simulation trajectory.

For the climbing test, the input speed of the vehicle was set to $0.1 \mathrm{~m} / \mathrm{s}$, while the lab field slope was approximately 26.5 degrees. Fig. 4 compares the pitch angles between the test and the simulation. The changes in the observed trends matched each other well, in spite of position differences of the mass centre between the real vehicle and the simulation model.

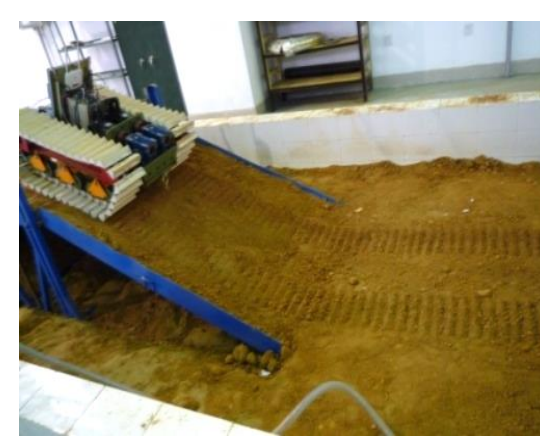

a)

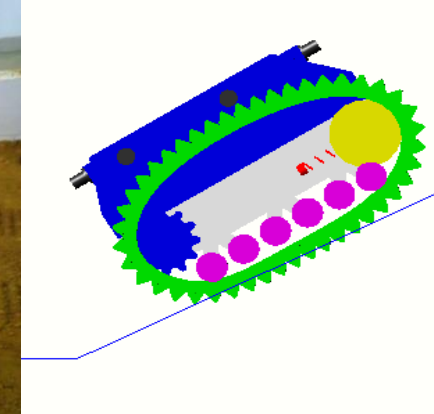

b)

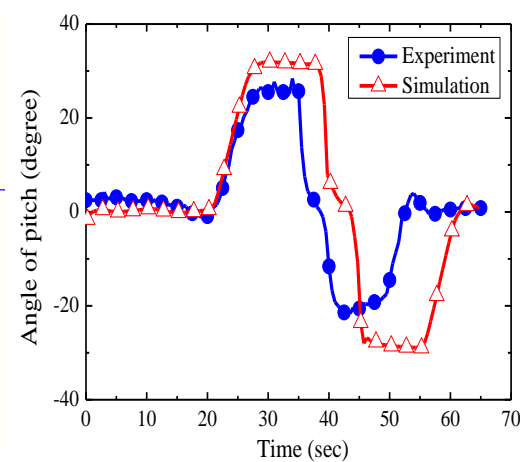

c)

Figure 4: Climbing test and simulation of a tracked vehicle: a) photo of the test; b) simulation model; and c) pitch angle.

These results demonstrate that the computational accuracy of the simulations is sufficient, and this method can be utilized effectively to develop a virtual prototype model of a seabed tracked ROV given the special terramechanics properties of the seafloor soil.

\section{SIMULATION MODEL OF A ROV HYDRAULIC CONTROL SYSTEM}

A LUDV hydraulic control system consists a variable displacement pump, load sensing (LS) pressure-compensated values, multi-tandem direction values, actuators, oil lines, etc.; an LUDV is suitable for a multi-actuators system and is nearly unaffected by loads changes. 
Considering the seabed ROV needs to perform combined motions with high accuracy, the LUDV hydraulic system is considered and adopted. Compared to general LS hydraulic system, the main feature of the LUDV is that the pressure-compensated valve is arranged after the multi-tandem direction value. The maximum actuator pressure is transferred to the pressure-compensated valve and the variable displacement pump. For this reason, the flow distribution for each actuator is irrelevant to the load and is only directly proportional to the openness of the throttle valve. The flow and pressure characteristics for the LUDV hydraulic control system are analysed as follows.

The pressure difference of the main valve port is computed as:

$$
p_{p}-p_{L 1}=p_{p}-p_{L 2}=p_{p}-\left(\frac{F_{0}}{A_{0}}+p_{L S}\right)
$$

where $F_{0}$ is the spring preload of the pressure compensator; $A_{0}$ is the pressure area of the end face of the compensator valve core; $P_{p}$ is the pump outlet pressure; $P_{L 1}$ and $P_{L 2}$ are the inlet pressures of the compensators correspond to different actuators, respectively.

The demanded flow for each actuator and the total flow are computed as:

$$
\left\{\begin{array}{l}
q_{L i}=C_{d} W_{i} X_{i} \sqrt{\frac{2}{\rho}\left(p_{p}-p_{L S}-\frac{F_{0}}{A_{0}}\right)}, \quad i=[0, \ldots, n] \\
q_{L}=q_{L 1}+q_{L 2}+\ldots+q_{L \mathrm{n}}
\end{array}\right.
$$

where $C_{d}$ is the flow coefficient; $p$ is hydraulic oil density; $q_{L i}$ is the flow for the $i^{\text {th }}$ actuator; $W_{i}$ and $X_{i}$ represent the flow area gradient and openness of the throttle valve; $q_{L}$ is the total demanded flow for all the actuators.

From Eqs. (1) and (2), the relation between the demanded flow for each actuator and total flow is:

$$
\frac{q_{L i}}{q_{L}}=\frac{C_{d} W_{i} X_{i} \sqrt{\frac{2}{\rho}\left(p_{p}-p_{L S}-\frac{F_{0}}{A_{0}}\right)}}{C_{d} W_{i}\left(X_{1}+X_{2}+\ldots+X_{n}\right) \sqrt{\frac{2}{\rho}\left(p_{p}-p_{L S}-\frac{F_{0}}{A_{0}}\right)}}=\frac{W_{i} X_{i}}{\sum_{k=1}^{n} W_{k} X_{k}}
$$

The following equation can be obtained from above Eq. (3):

$$
\frac{q_{L}}{\sum_{k=1}^{n} W_{k} X_{k}}=C_{d} \sqrt{\frac{2}{\rho}\left(p_{p}-p_{L S}-\frac{F_{0}}{A_{0}}\right)}
$$

Consequently, the pump outlet pressure and the system pressure margin can be calculated as follows:

$$
\left\{\begin{array}{l}
p_{p}=p_{L S}+\frac{F_{0}}{A_{0}}+\frac{1}{\left(C_{d}\right)^{2}} \frac{2}{\rho}\left\{\frac{q_{L}}{\sum_{k=1}^{n} W_{k} X_{k}}\right\}^{2} \\
\Delta p=\frac{1}{\left(C_{d}\right)^{2}} \frac{2}{\rho}\left\{\frac{q_{L}}{\sum_{k=1}^{n} W_{k} X_{k}}\right\}^{2}
\end{array}\right.
$$

It can seem that the pressure-compensated valve arranged after the main valve in the LUDV hydraulic system has a flow share and allocate function. Regardless of working 
condition, the provided flow from the system can be supplied to each actuator by proportionally regulating the openness of the control value according to the control signal, to guarantee the manoeuvrability performance of the system.

The BOSCH-REXROTH constant-power variable displacement pump and M7 multi-tandem value were used to construct the LUDV hydraulic control system for the seabed tracked ROV. Fig. 5 shows the principal schematic diagram. Table II gives the key parameters of the hydraulic components.

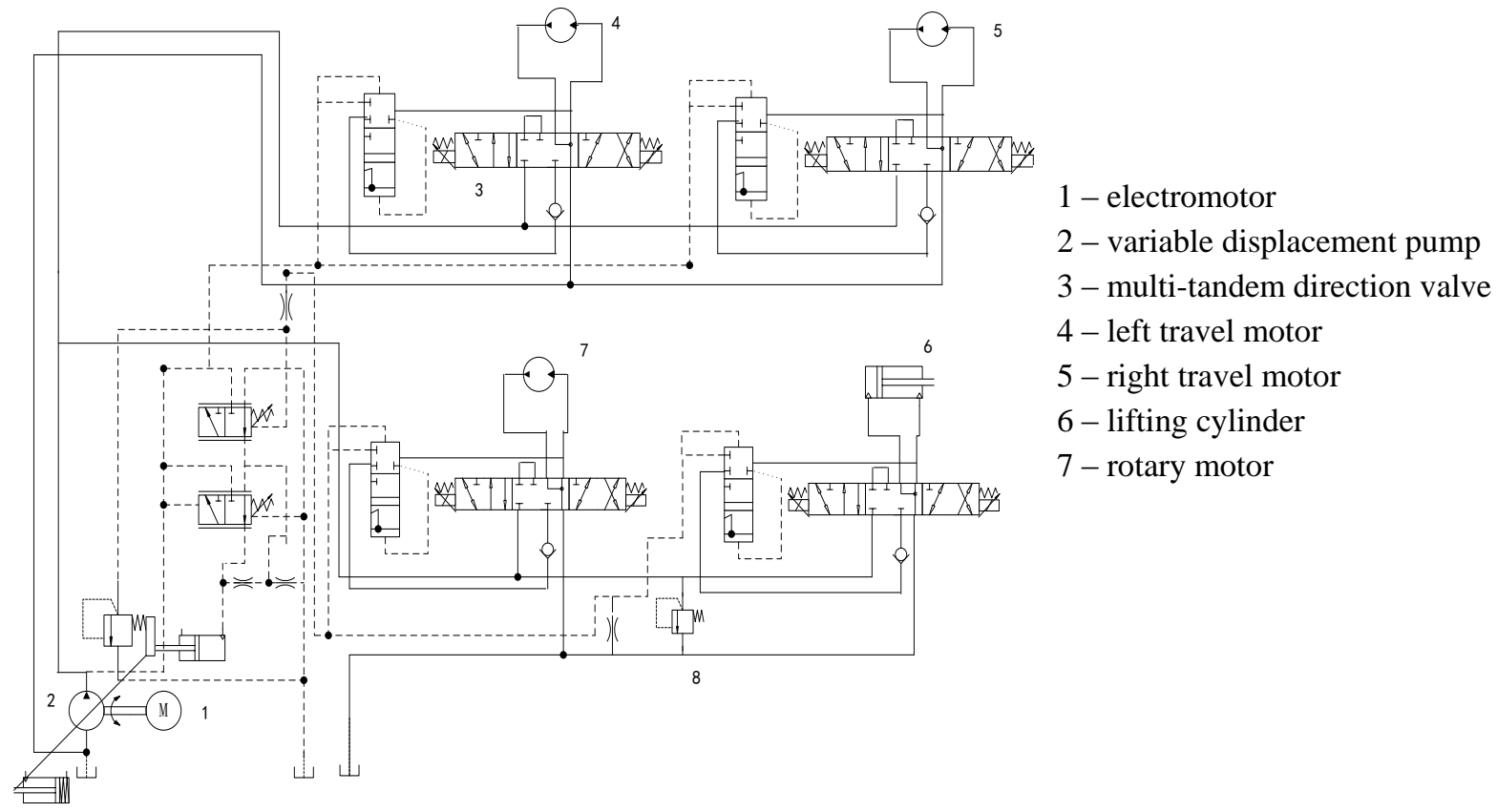

Figure 5: Principal schematic diagram of the hydraulic control system for the seabed tracked ROV.

Table II: Key parameters of the hydraulic components.

\begin{tabular}{|l|c|}
\hline \multicolumn{1}{|c|}{ Parameters } & Values \\
\hline Pump displacement (ml/r) & 50 \\
\hline Rated discharge pressure of pump (MPa) & 35 \\
\hline Maximum speed of the electromotor (r/min) & 2500 \\
\hline Displacement of travel motor (ml/r) & 18 \\
\hline Diameter of piston rod (mm) & 35 \\
\hline Mass of control valve spool $(\mathrm{kg})$ & 0.01 \\
\hline Diameter of control valve spool (mm) & 5 \\
\hline Orifice diameter of throttle valve at maximum opening $(\mathrm{mm})$ & 1.46 \\
\hline
\end{tabular}

AMESim was used to establish a simulation model of the above LUDV hydraulic control system for the seabed tracked ROV. The actual mechanical structural models of the variable displacement pump and the values were built by the AMESim hydraulic component design (HCD) library and packaged into super elements. Based on the interface program design between RecurDyn-AMESim, the virtual mechanical system prototype model of the tracked ROV can be integrated into the simulation model of its hydraulic control system in the AMESim environment as shown in Fig. 6. This integration can realize the real-time information exchange between the two simulation models. 


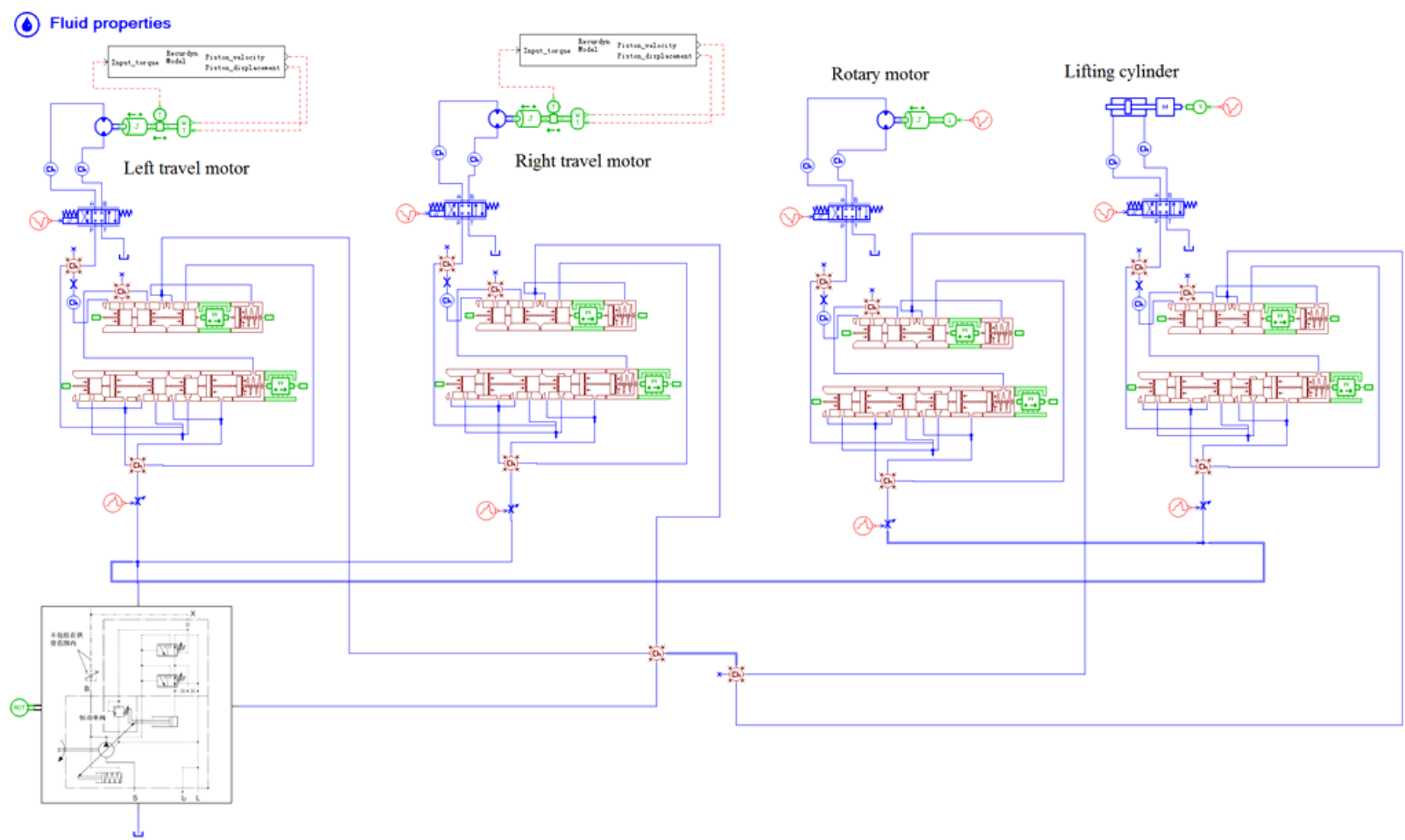

Figure 6: Mechanical-hydraulic co-simulation model of the seabed tracked ROV.

\section{OPERATIONAL PROCESS CO-SIMULATION ANALYSIS}

Based on the co-simulation, the motion velocity of the tracked ROV model in RecurDyn can be controlled by the inlet flow of its travel motors models in AMESim. In the LUDV hydraulic system, the flow is controlled by the opening signal for the variable throttle valve.

For the straight-line motion simulation of the tracked ROV, the opening signals for both the variable throttle valves in the hydraulic system are set to 0.06 , with which the target speed for the tracked ROV sprocket can be controlled to approximately $0.6 \mathrm{~m} / \mathrm{s}$. Fig. 7 illustrates the operational process co-simulation results of the mechanical-hydraulic system when the tracked ROV is moving on homogeneous sediment. The motion velocity of the tracked ROV in RecurDyn can be controlled well with appropriate control of the flow and rotation speed of the travel motors in AMESim.

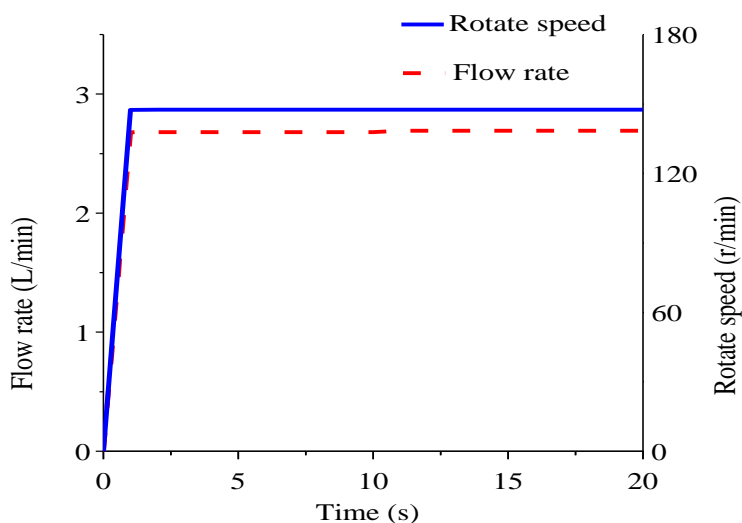

a)

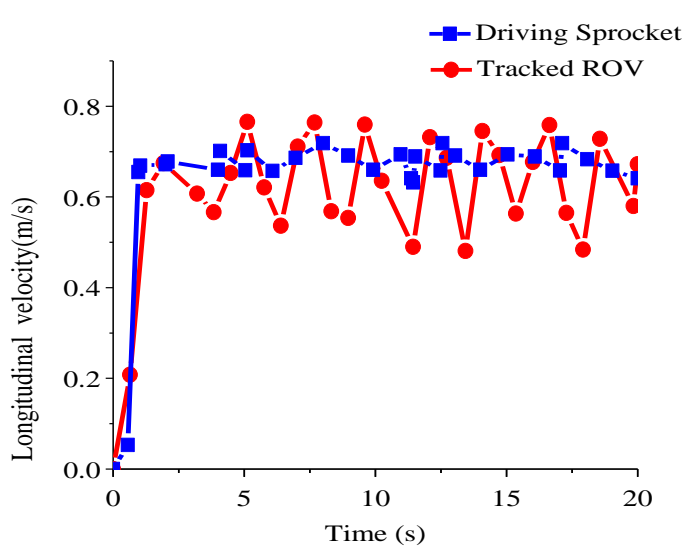

b)

Figure 7: Co-simulation results of the mechanical-hydraulic system when the tracked ROV moving on a homogeneous sediment: a) flow rate and rotate speed simulation curves of the travel motor; b) longitudinal motion velocities of the driving sprocket and tracked ROV. 
Fig. 8 presents the operational process co-simulation results in the case where the shear strength of the sediment under both ROV tracks was different, while the openness signals of the variable throttle valves for both the motors in the hydraulic system remain unchanged. The driving torques are different because the different shear strengths under the tracks can produce different shear traction forces. Accordingly, the load pressures for the motors are different. However, under the above conditions, the motion speeds of both ROV tracks are nearly identical. It can be concluded that the flow is unaffected by the travel motor's load; the load is independent of the flow. It is clearly advantageous with this hydraulic control system that regardless of the travel motor load changes, its rotation speed remains constant, and the motion state of each ROV track remains unchanged.

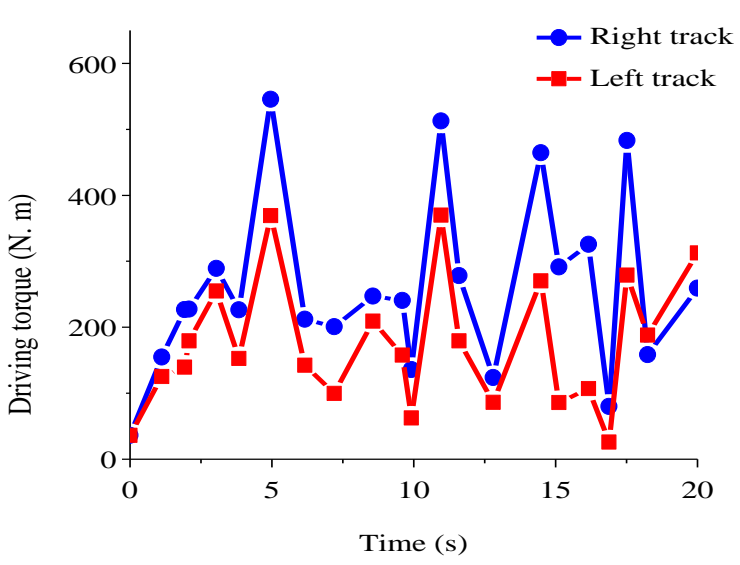

a)

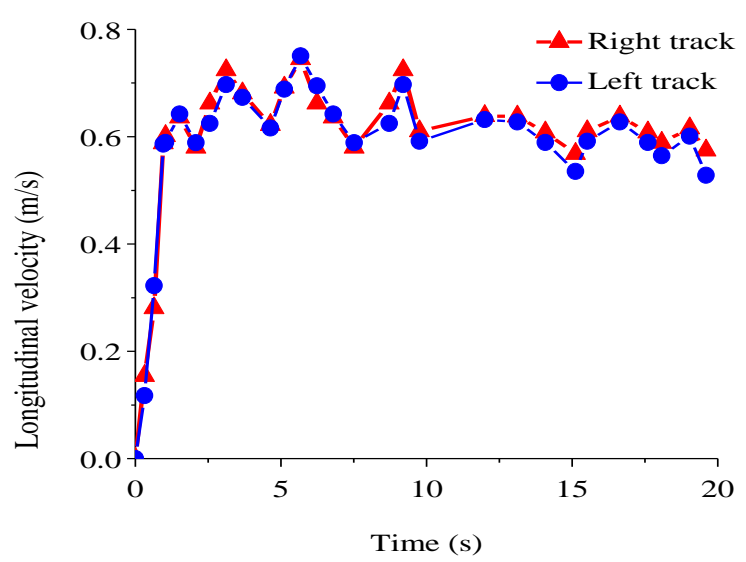

c)

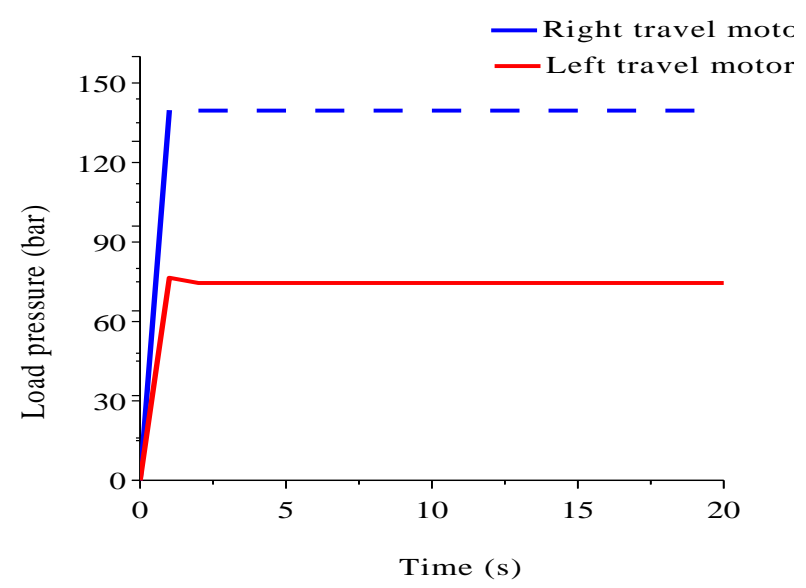

b)

Figure 8: Co-simulation results of the mechanical-hydraulic system when the tracked ROV moving on an inhomogeneous sediment: a) driving torque of left and right tracks; b) load pressure of travel motors; and c) longitudinal velocity of left and right tracks.

The ideal turning velocity ratio for the outer and inner tracks of a seabed tracked ROV on the sediment should not exceed 1.4 to ensure safety. A ratio of 1.2 and 1.4 are set with a target velocity of $0.5 \mathrm{~m} / \mathrm{s}$ for the inner track, while the openness signals for the variable throttle valves are defined as 0.05 and $0.06,0.07$. Fig. 9 illustrates the turning trajectory simulations. The turning radii of the tracked ROV on the seabed are approximately $25 \mathrm{~m}$ and $30 \mathrm{~m}$ for different turning velocity ratios. A slip phenomenon obviously occurs for locomotion on the seabed. Thus, stricter requirements are necessary for path planning and control for a seabed tracked ROV. 


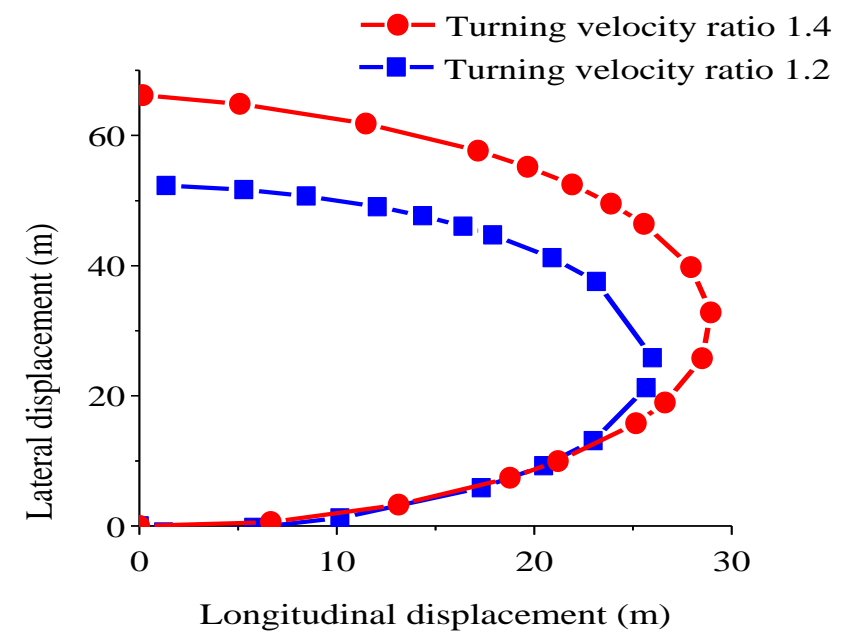

Figure 9: Simulation trajectories of a seabed tracked ROV with different turning velocity ratios.

\section{CONCLUSIONS}

The following major conclusions can be drawn from this study:

(1) A new virtual prototype model of a seabed tracked ROV has been developed using RecurDyn/Track with an integrated user-defined sediment terramechanics model subroutine. The modelling method and computational accuracy of the new virtual prototype model have been validated by laboratory motion tests of a small-scale tracked vehicle.

(2) A simulation model of a load independent flow distribution (LUDV) hydraulic control system for the seabed tracked ROV has been established using AMESim. Based on the combined RecurDyn-AMESim interface program design, a new virtual prototype co-simulation model for the mechanical-hydraulic system of the ROV has been developed. The real-time information exchange and collaborative simulation computing between the two systems have been realized.

(3) The operational process co-simulations results demonstrate that the virtual prototype model of the ROV mechanical system can accurately simulate the load for the hydraulic control system; meanwhile, the motor speed is nearly unaffected by the load change and has no direct relationship with the maximum rated flow of the variable displacement pump. The flow only depends on the openness of the variable throttle valve. As a result, with this hydraulic control system, the motion state of the tracked ROV driving system is not affected by the environmental load changes.

\section{ACKNOWLEDGEMENTS}

This research is supported by the National High Technology Research and Development Program (Grant No. 2012AA091201), the Knowledge Innovation Foundation Research Project of Shenzhen Science and Technology Program (Grant No. JCYJ20130401160614378), and the State Key Laboratory of Ocean Engineering at Shanghai Jiao Tong University (Grant No. 201515).

\section{REFERENCES}

[1] Kim, H.-W.; Hong, S.; Choi, J.-S.; Yeu, T.-K. (2006). Dynamic analysis of underwater tracked vehicle on extremely soft soil by using Euler parameters, Journal of Ocean Engineering and Technology, Vol. 20, No. 6, 93-100

[2] Kim, H.-W.; Lee, C.-H.; Hong, S.; Oh, J.-W.; Min, C.-H.; Yeu, T.-K.; Choi, J. (2013). Dynamic analysis of a tracked vehicle based on a subsystem synthesis method, Proceedings of the $10^{\text {th }}$ ISOPE Ocean Mining and Gas Hydrates Symposium, 279-285 
[3] Kim, H.-W.; Hong, S.; Lee, C.-H.; Choi, J.-S.; Yeu, T.-K. (2011). Dynamic analysis of an articulated tracked vehicle on undulating and inclined ground, Proceedings of the $9^{\text {th }}$ ISOPE Ocean Mining Symposium, 97-103

[4] Lee, C.-H.; Kim, H.-W.; Hong, S. (2011). A study on the driving performance of tracked vehicle on an inclined plane according to the position of buoyancy, Proceedings of the $9^{\text {th }}$ ISOPE Ocean Mining Symposium, 104-109

[5] Li, L.; Zhong, J. (2005). Research of China's pilot-miner in the mining system of poly-metallic nodule, Proceedings of the $6^{\text {th }}$ ISOPE Ocean Mining Symposium, 124-131

[6] Dai, Y.; Zhu, X.; Chen, L. S. ; Liu, H.; Zhang, T.; Liu, S. J. (2015). A new multi-body dynamic model for seafloor miner and its trafficability evaluation, International Journal of Simulation Modelling, Vol. 14, No. 4, 732-743, doi:10.2507/IJSIMM14(4)CO19

[7] Dai, Y.; Chen, L. S.; Zhu, X.; Liu, H. (2016). Modelling and simulation of a mining machine excavating seabed massive sulfide deposits, International Journal of Simulation Modelling, Vol. 15, No. 2, 377-387, doi:10.2507/IJSIMM15(2)CO10

[8] Herzog, K.; Schulte, E.; Atmanand, M. A.; Schwarz, W. (2007). Slip control system for a deep-sea mining machine, IEEE Transactions on Automation Science and Engineering, Vol. 4, No. 2, 282-286, doi:10.1109/TASE.2006.879688

[9] Yeu, T. K.; Park, S. J.; Hong, S.; Kim, H. W.; Choi, J. S. (2006). Path tracking using vector pursuit algorithm for tracked vehicles driving on the soft cohesive soil, SICE-ICASE International Joint Conference, 2781-2786

[10] Yeu, T.-K.; Yoon, S.-M.; Park, S.-J.; Hong, S.; Kim, H.-W.; Lee, C.-H.; Choi, J.-S.; Sung, K.-Y. (2011). Study on underwater navigation of crawler type mining robot, Oceans 2011 (MTS/IEEE KONA), 6 pages

[11] Yoon, S.-M.; Yeu, T.-K.; Hong, S.; Kim, J.-H.; Kim, H.-W.; Lee, C.-H.; Min, C.-H.; Choi, J.-S. (2014). Path tracking control test of underwater mining robot, Oceans - St. John's 2014, 4 pages, doi:10.1109/OCEANS.2014.7003040

[12] Florin, I. (2007). Modelling and simulation in mechatronics, IFAC Proceedings Volumes - The $4^{\text {th }}$ International Federation of Automatic Control Conference on Management and Control of Production and Logistics, Vol. 40, No. 18, 301-312, doi:10.3182/20070927-4-RO-3905.00051

[13] Marquis-Favre, W.; Bideaux, E.; Scavarda, S. (2006). A planar mechanical library in the AMESim simulation software. Part II: Library composition and illustrative example, Simulation Modelling Practice and Theory, Vol. 14, No. 2, 95-111, doi:10.1016/j.simpat.2005.02.007

[14] Zhang, H.-M.; Wang, H.-W.; Chen, D.; Zacharewicz, G. (2010). A model-driven approach to multidisciplinary collaborative simulation for virtual product development, Advanced Engineering Informatics, Vol. 24, No. 2, 167-179, doi:10.1016/j.aei.2009.07.005

[15] Huang, J.-H.; Dong, Z.-X.; Quan, L.; Jin, Z.; Lan, Y.; Wang, Y. (2015). Development of a dual displacement controlled circuit for hydraulic shovel swing motion, Automation in Construction, Vol. 57, 166-174, doi:10.1016/j.autcon.2015.06.006 